\title{
Research on the Development of Guangxi Bulk Commodity Trading and Market Construction
}

\section{Xiaoming Qiao}

Journal Editorial Department, Yunnan Normal University, Kunming, Yunnan, 650092

Keywords: Guangxi, bulk commodity, commodity trading, market construction

\begin{abstract}
Bulk commodity trading is established in accordance with the laws, which is a public, regular or periodic bulk commodity exchange activity by the seller and the buyer. The standard and normal expansion of commodity trading can improve the efficiency of the commodity circulation, promote regional industrial accumulation and cooperation, and play a leading and fundamental role . This paper combines the actual situation to discuss on bulk commodity trading and market construction from three aspects such as the development status, trends and conditions in Guangxi.
\end{abstract}

\section{Introduction}

Commodity refers to the bulk commodities that can enter into the circulation of commodities, have the attributes of commodities but not in the retail sector, and are used for the mass production and consumption of industrial agriculture, mainly including energy commodities, industrial raw materials and agricultural products. Commodities related to people's livelihood, with price volatility, supply and demand, easy to grade and standardize, easy to store, transport characteristics. In the process of developing commodity trading and market building, Guangxi fully utilizes its geographical advantages, resources advantages and market advantages to organically link commodity trading and market construction with production, processing and trading enterprises.

\section{The development status: steady progress, initial size}

Located in the core area of the Beibu Gulf Economic Zone, Guangxi is an engine of economic growth that serves the southwest, south China, central and southern regions and Southeast Asian countries. It will promote the enlargement of the policy effects of the western development and narrow the economic gap between the east and the west. The hinterland economy and foreign trade are interlinked with each other, providing in-depth market demand and industrial support for the development of Guangxi's commodity trading and markets. In the process of commodity trading and market construction in Guangxi, we broke the geographical and time constraints, nurtured markets and investors and transformed regional advantages and product advantages into competitive advantages in the market to attract the powerful shareholders and funds in the developed eastern regions and introduce new concepts and advanced technology, management and personnel, to promote innovation in production and supply system. Xinhua Commodity Trading Center was established on May 29, 2015 and has set up a regional operation center in Chongqing, Hubei, Henan, Jiangsu, Fujian, Jiangxi, Hunan and Shaanxi provinces. The Xinhua Bulk Guangxi Operations Center was set up in December 2014 to take advantage of its market, capital and management advantages to integrate the commodity resources, logistics, information and capital flows in Guangxi into an organic whole that focuses on circulation and links the entire chain of production and information Management mechanism to cultivate the factor market in the western region.

Guangxi is one of the provinces with large commodity trading markets in China. It owns 4 large state-owned cocoon wire trading markets in Guangxi, Guangxi sugar net sugar wholesale market, Xinhua bulk Guangxi operation center and Guangxi Beibu Gulf mineral trading center, As well as six privately owned bulk commodities such as Nanning (China-ASEAN) Commodity Exchange, Guangxi Sugar Center Wholesale Market, Guangxi Guangnan International Commodity Exchange, 
Nanning Commodity Exchange, Guangxi Southwest Coal Trading Center and Guangxi Nongken Agricultural Products Electronic Trading Market Trading market; registered in the trading market concentrated in Nanning City, Liuzhou City and Guigang City. The main varieties listed on the market are food, agricultural products, chemicals, metallurgy, coal and other industries in 21 resource-based products in Guangxi.

Guangxi Commodity Exchange Management Department actively promoted the transformation of the trading markets to the spot market, paid close attention to its operational dynamics, and utilized modern information means to actively develop e-commerce, promote and improve the transaction modes of agreement transfer and auction. For example, Guangxi Sugar Sugar Sugar Market grasped the policy boundary and put an end to the standardization contract transaction through the centralized trading such as electronic matching, centralized bidding, anonymous trading and market maker, etc., and focused on sorting out and perfecting the cash on the spot e-commerce transaction process, highlighting the non-standardization The physical trading model, focusing on creating cash to provide stock, warehousing and distribution and other cash support for the core sugar industry service platform. In 2015, the total turnover of sugar trading in four sugar trading markets accounted for nearly 53\% of the total output of sugar in China, which played an active role in the formation of China's sugar commodity trade and the spot price of sugar. Guangxi Guangnang International Commodity Exchange, established in February 2009, mainly deals in bulk commodities such as methanol, sugar and molasses, and is the only commodity trading venue integrating chemicals and agricultural products in China-ASEAN region. According to market needs, we will systematically excavate commodity resources on both sides and promote the circulation of bulk commodities in the two places.

In order to effectively prevent market risks under the existing imperfections in laws and regulations, a series of regulatory measures have been taken by Guangxi Commodity Trading Administration and various trading markets to focus on strengthening the trading rules for commodities, Market risk control, cash settlement, fund settlement and other aspects of management. Nanning (China-ASEAN) Commodity Exchange, according to the characteristics of the trades and other industries, continue to improve and adapt to different trading varieties spot electronic electronic trading contract. Guangxi Nongken agricultural electronic trading market strictly implement the dealer access system, put an end to all natural persons and enterprises without industry background market transactions.

Commodity trading market as an independent body, which can be settled in the market for enterprises to provide capital transaction settlement services, but can not completely control the business of funds transactions. To this end, Guangxi commodity trading markets to strengthen the transaction funds management: First, the bank signed a fund settlement agreement, such as Guangxi Southwest Coal Center and Guangxi Sugar Network and Agricultural Bank of China, ICBC, Bank and other banks to establish an automatic transfer system. The second is to open a trading margin account at the bank, which stipulates that the margin account should be used to collect the deposit of investor transactions. Third, according to the directive, banks will automatically transfer funds between the investor's individual account and the market margin account through the commercial bank transfer system. Fourth, the margin account funds owned by investors, in addition to the agreed use, the market shall not be transferred to its designated account of funds. Fifth, banks and the market daily electronic reconciliation. Each trading market also standardizes the form of deposit payment, according to the provisions of the margin for both buyers and sellers increased to 20\%, and most of the margin buyers and sellers are paid by cash.

The Guangxi Commodity Exchange has set up a place and Internet trading platform with supporting services such as information and logistics to realize the information transfer and interaction among enterprises and customers. Commodity trading requirements of the collection and distribution network is higher, at this stage in Guangxi bulk commodity transport network with the main road and railway. Guangxi Southwest Coal Trading Center integrates the resources of the neighboring coal spot trading, vigorously develops the spot listed electronic trading platform, closely connects the production, processing and trading enterprises through the trading platform, 
and promotes the specialization and intensive development of the trading market. Guangxi bulk cocoon silk market to consolidate and improve e-commerce + modern logistics model, improve the purchase and sale contract agreement transfer mechanism and further increase storage and logistics facilities and distribution service network construction efforts, and gradually formed to existing e-commerce + modern logistics mainly, Spot listing, supply and demand and auction sales supplemented by the purchase of goods integrated platform for goods.

In the course of commodity trading and market construction in Guangxi, some trading markets lack a systematic and clear understanding of the core issues such as domestic spot trading, spot order trading and mid-to-spot trading of spot orders, resulting in their market positioning being inaccurate, resulting in management Passive in the process. In terms of trading commodities, the trading varieties set up by the existing commodity trading in Guangxi did not form a link with the key development industries in Guangxi at this stage, resulting in the fact that the type and structure of the commodities traded did not coincide with the focus of Guangxi's industrial and agricultural development and lacks the radiation capacity. In addition, the functional system of the commodity trading market in Guangxi is not yet perfect, with diversified market operations but insufficient cooperation mechanisms in various markets. Sugar-related industries are one of the most influential industries in Guangxi in the country. Of the four existing commodity markets that involve sugar-related products, two are specialized sugar trading markets and two are integrated trading markets that easily lead to the same Commodity transactions compete with each other.

\section{The development trend: highlighting the market characteristics, for commodity pricing}

Set up a commodity trading market facing the China-ASEAN Free Trade Area. Guangxi is the only province that connects China with the land and sea of Southeast Asian countries. It has convenient access to the sea and the most complete special customs control zone in the country. In recent years, China's import and export trade with ASEAN countries has continued to grow. In 1991, the bilateral trade volume was only 7.96 billion U.S. dollars. In 2015, it reached 472.16 billion U.S. dollars, an average annual growth rate of $18.5 \%$. Its share of China's foreign trade increased from 5.9\% in 1991 to $11.9 \%$ in 2015. In 2015, Guangxi's import and export to ASEAN countries reached 28.6 billion U.S. dollars, up $19.6 \%$ over the same period of previous year, accounting for $56.6 \%$ of the total foreign trade value of Guangxi in the same period. In terms of the import and export of bilateral commodity trade, the commodities exported through the ports of Guangxi mainly include minerals, vegetables, refined oil, steel, textiles and fertilizers. Imports are made of raw materials and energy sources such as crude oil, refined oil, plastic raw materials, natural rubber, coal and iron ore, and agricultural and forestry products such as cereals, vegetables, fruits, sugar, fish, herbs, wood and wood products.

Guangxi should seize the "new round of economic growth point" and increase the level of cooperation with foreign countries, with a focus on the establishment of an international commodity trade distribution and resources for the China-ASEAN free trade area in four regions: bonded areas, coastal ports, border crossings and central cities configure the platform. The establishment of a commodity trading market in Guangxi facing the China-ASEAN Free Trade Area will greatly enhance the influence of key industries and products in China and Guangxi [1]. The real economy and financial instruments of both sides are connected and combined through the trading platform. Around the trading platform, traders, international brokers and settlement members of the world are attracted to enter the market of Guangxi so as to realize the innovation and upgrade of the export-oriented commodities trading market.

Establishing the commodity trading market facing the domestic economic hinterland. With the rapid economic growth in the hinterland of Guangxi Zhuang Autonomous Region, the five southwestern provinces including Guangxi, Yunnan, Guizhou, Sichuan and Chongqing, under the support of the policy of western national development, enjoyed steady growth in GDP. Among them, in the six years from 2011 to 2015, the average growth rate of GDP in the five southwestern provinces was $16.6 \%$. In the recent five years, Guangxi's GDP accounted for $19.33 \%$ of the GDP of five provinces in southwest China, second only to Sichuan's 37.39\%, ranking second. This trend of 
development strongly supports the development of commodity trade in Guangxi, which is geared towards the domestic economic hinterland.

First, strengthen the construction of trading market. From the perspective of circulation, China's commodity market will enter a period of improvement. From a business perspective, the main bulk commodities in China will enter a period of transition [2]. The development of commodity trade in Guangxi should correspond to the development of regional economy. It should continue to integrate resources within and outside the region, optimize the structure of the trading market, comprehensively enhance the overall quality of the industry and promote the development of regional economy. Commodity trading markets across Guangxi should actively create the conditions to attract enterprises to enter the market and enhance the brand effect of the market. At the same time, local conglomerates should also be nurtured to participate in the commodity trading platform.

Second, the formation of commodity agglomeration. The commodity varieties of commodities traded in Guangxi are increasingly rich: the first is the kinds of commodities imported from ASEAN countries, and the other is Guangxi's dominant commodities such as coal, manganese industry, phosphorous, gum rosin, and agricultural and forestry products such as grain and oil, sugar, Timber and its products, fruits, fish, herbs and more. Guangxi should, in light of its own resource conditions, market conditions, changes in the mode of bulk commodity trade and the trend of economic development both at home and abroad, choose to trade with competitive varieties.

The acquisition of commodity pricing rights depends on market and market influence. China has no voice in the pricing power of commodities, resulting in very little profit margin for the domestic manufacturing industry. The lack of pricing power will become a constraint on China's industrial structure toward high-end and from a manufacturing power to a manufacturing power [3]. The glycosylated sugar products in Guangxi sugar net trading in Liuzhou City of Guangxi Province have generated the "Liuzhou Price" and effectively played the role of Guangxi as the spot benchmark price of the main sugar producing areas and became the benchmark for the price of sugar in the country. In order to win the pricing power of commodities and consolidate the pricing power, the commodities trading in Guangxi must first fully understand the importance of pricing power for enterprises to avoid risks, allocate resources rationally and effectively, safeguard the economic security of the country and enhance China's international influence. Concentration and cooperation among manufacturing enterprises, improve the investor structure, and enhance Guangxi's bargaining power and pricing power in commodity trading. Second, in order to establish and improve the commodity structure and market system in Guangxi, Guangxi should continuously enhance the pricing power of commodities, embody the "Guangxi factor" more in the domestic and international commodity trade, make use of the existing trading bases and promptly launch corresponding price indices. In order to form a regional market influence.

To find trade opportunities, and gradually grasp the pricing power of discourse. The volatility of commodity prices reflects the changes in the basic needs of commodities [4]. Xinhua bulk operations center in Guangxi, China, Guangxi and ASEAN countries based on the strong complementary features of commodity trading, "around the spot service, nurturing brands, to promote settlement development ideas," has launched the PTA, MEG, copper, 13 varieties such as cotton, yarn, green tea, black tea, gum rosin, garlic, pine nuts, incense sticks, silver and crude oil have achieved remarkable social and economic benefits and have strengthened the right to speak of bulk commodities in bulk commodities.

Establish a market price system. The increasingly fierce competition among the domestic commodity markets and the fact that the selected trading varieties in Guangxi have the same or similarities with other domestic market choices have made the "pricing center" a target for competition. Guangxi should strengthen the transparency of information disclosure and the management of alliances in the industry and set up an early warning mechanism for commodity prices [5]. It will produce the most influential prices in commodity transactions and raise the voice and pricing power of commodity trading in Guangxi so as to grasp the market initiative right. 


\section{The development conditions: improve management, standardize the business}

Guangxi construction for the two domestic and foreign commodity trading service system is a cross-sectoral, cross-sectoral and trans-regional systems engineering, it is necessary to closely with the relevant state departments, the surrounding areas, the existing market communication and coordination; to the scientific concept of development Guide and adhere to government-led, market-oriented and business-oriented entities. With the support of advanced technologies and information technology, we will actively promote specialized and socialized commodities trading services and provide services in the areas of southwest, central and southern China, southern China, radiation inland, connecting ASEAN and the rest of the world, Have some influence at home and abroad in Guangxi bulk commodity markets.

At present, the development of the domestic spot market is not perfect and should be based on the establishment of a standardized spot trading platform and it's docking with the corresponding domestic and international futures markets [6]. Guangxi First, we must clarify the main functions and functions of the management department, establish and improve the trading system and mechanism, the introduction of the corresponding trading rules, market regulations and industry qualifications and other management regulations. Second, we must set up a special management agencies to strengthen the supervision of the trading behavior and market operation, and timely rule out trading risks and market risks. Third, it is necessary to strengthen the linkage with the financial markets and promote the development of a series of financial businesses related to the settlement of funds related to commodity transactions, commodity guarantees, pledge of warehouse receipts, and payment for goods.

Risk control is the key to the success or failure of the development of commodity trading. Since there is no clear market management entity for commodity trading at this stage, the barrier to entry is low and the risk exposure obviously does not match the scale of its operation. Managers are free to change the trading rules during the market operation, as well as the lack of early warning of risks, resulting in heavy trading and market risks. To this end, Guangxi, a timely adjustment of business strategy and production direction, clearly not to focus on standardized trading transactions; Second, we must do a good job of risk prediction, to develop a variety of risk aversion and response programs; Third, the trading behavior must be monitored from time to time, strict Check each settlement, the delivery process of the implementation of the whole process of strict control, effective control and timely disposal of trading risk; Fourth, to implement the trading varieties differentiation strategy to avoid competition in the same place, and actively participate in off-site interbank market, improve the overall industry anti-competition The ability to risk.

In the construction of market information service platform, Guangxi needs to conduct a large market (Guangxi Commodity Exchange Market), three major platforms (commodities trading platform, commodities information platform, commodities Service platform), the layout of the eight functions (production and daily service, wholesale in modern market, product distribution, product processing and distribution, e-commerce transactions, product display activities, intermodal transport and park management services) service system.

Commodity trading and upstream and downstream enterprises there is a strong correlation and adhesion, which will bulk commodity trading parties and commercial activities into the entire supply chain system, use of limited resources to shorten the trade cycle. In order to do a good job in commodity trading and supply chain integration, first, Guangxi should integrate and optimize information flow, logistics and capital flow in the supply chain to form a worldwide commodity supply chain management system so as to gain the competitive advantage of the enterprise. Commodity trading platform plays the role of integrator of various logistics resources. By integrating its own logistics resources or social logistics resources, the platform can realize the whole logistics service function of trading platform [7]. Second, the introduction of well-known commodity operators and traders, using its market network and management experience, to build a corporate supply chain management system based in Guangxi commodity trading market. Third, to achieve cloud supply, cloud logistics and cloud management, improve the supply chain management of bulk commodities, and gradually form the exchange of information and real-time 
exchange among transactions, logistics, warehousing and ports and railways. Through the standardized trading platform service, the seamless integration of commodities trading and warehousing, logistics, liquidation and financial system can be realized, the commodity ecosystem can be built, the efficiency of all aspects of commodity circulation can be improved, and the added value in the circulation chain of bulk commodities can be increased.

Guangxi in the process of building a commodity trading market system, we must strengthen the theoretical basis of the commodity trading market areas to learn advanced management practices and operational experience at home and abroad to improve the statistical system of commodity trading. Clear the statistical system, method and evaluation index system in the concrete work, promptly and accurately reflect the market's development scale and operational efficiency, and provide reference for the government's macro-management and enterprise management decision-making. Guangxi Commodity Trading Industry Association shall serve the general membership, safeguard the legitimate rights and interests of its members, maintain market order and security, do a good job in investigation and research, information statistics, consulting services and international cooperation, and give full play to the bridges of trade associations and Tie effect. At the same time, the implementation of self-management industry, self-supervision, self-coordination, and actively promote the industry standard self-discipline and integrity system.

\section{References}

[1] Li Yan. Research on the Development of Guangxi Commodity Electronic Transaction Market Facing China-ASEAN Free Trade Area [J]. Southeast Asia, 2013 (6): 40-44.

[2] Cai Jin. Commodity Market Development Trend and Innovation [J]. China's Circulation Economy 2013 (12): 6-9.

[3] Weng Xingang, Ann long Italy. Entire full range of commodities logistics e-commerce content and model [J]. 2013 (12): 191-194.

[4] Lv Zhiping. Research on the financial problems of commodities [J]. Hubei Social Sciences, 2013 (2): 77-80.

[5] Deng Chuang, Song Nan, Xia Bing. Time-Varying Impact of the Changes of International Commodity Prices on China's Price [J]. Management Modernization, 2015 (4): 112-114 (in Chinese)

[6] Lin Zuoming, Liu Qingqing. Commodity economy war status, trends and China's countermeasures [J]. Shanghai Institute of Public Administration, 2015, 16 (3): 11-22.

[7] Chu Xiaoming, Li Yanping. Research on Commodity Market Operation and Trading Patterns [J]. China Market, 2013 (19): 67-73. 